\title{
Clases medias y producción de ciudad: un análisis de la implementación del PROCREAR en La Plata (2013-2015) desde las prácticas de su población beneficiaria
}

\author{
Relli Ugartamendía, Mariana \\ Clases medias y producción de ciudad: un análisis de la implementación del PROCREAR en La Plata \\ (2013-2015) desde las prácticas de su población beneficiaria \\ Geograficando, vol. 16, núm. 1, 2020 \\ Universidad Nacional de La Plata, Argentina \\ DOI: https://doi.org/10.24215/2346898Xe071
}

Atribución no comercial compartir igual (CC BY-NC-SA) 4.0 


\section{Clases medias y producción de ciudad: un análisis de la implementación del PROCREAR en La Plata (2013-2015) desde las prácticas de su población beneficiaria}

Mariana Relli Ugartamendia

DOI: https://doi.org/10.24215/2346898Xe071

Centro de Investigaciones Geográficas - Instituto de

Investigaciones en Humanidades y Ciencias Sociales -

Facultad de Humanidades y Ciencias de la Educación

- Universidad Nacional de La Plata - CONICET,

Argentina

Tesis de Doctorado en Estudios Urbanos. Universidad Nacional de General Sarmiento.

Autora: Violeta Ventura - (Centro de Investigaciones Geográficas - Instituto de Investigaciones en Humanidades y Ciencias Sociales - Facultad de Humanidades y Ciencias de la Educación - Universidad Nacional de La Plata - Consejo Nacional de Investigaciones Científicas y Técnicas)

Director: Juan Pablo Del Río - (Laboratorio de Investigaciones del Territorio y el Ambiente - Comisión de Investigaciones Científicas - Consejo Nacional de Investigaciones Científicas y Técnicas)

Codirectora: Natalia Cosacov - (Instituto de Humanidades - Consejo Nacional de Investigaciones Científicas y Técnicas)

Fecha de defensa: 17 de marzo de 2020

Entre el 22 de octubre y el 19 de diciembre de 2013, a partir de una convocatoria realizada por redes sociales entre beneficiarios/as del Programa de Crédito Argentino del Bicentenario para la Vivienda Única y Familiar (Procrear) en La Plata, unas mil quinientas personas, hasta entonces desconocidas entre sí, se organizaron para lograr la sanción de una ordenanza municipal que cambiara el uso - de rural a residencial-a un conjunto de tierras que iban a ser adquiridas para la construcción de viviendas financiadas por el programa. En ese lapso, crearon la organización "Lxs Terxs", cabildearon el municipio y la prensa local y consiguieron el compromiso del Intendente Pablo Bruera ${ }^{1}$ sobre la futura sanción de la ordenanza, salieron a la búsqueda de posibles terrenos para comprar, relevaron 500 hectáreas periféricas e iniciaron negociaciones con los propietarios. Durante los últimos nueve días de ese periodo, se creó y sumó al reclamo otra organización conformada ad hoc, Condominios Organizados La Plata (COLP), para incluir en la ordenanza la misma recalificación, pero sobre tierras rurales que habían sido adquiridas previamente en condominio. Y lo lograron.

A partir de la curiosidad que le despertó este episodio, Violeta Ventura aborda un tema significativamente ausente en los estudios urbanos: la producción de ciudad de las clases medias. Analiza las formas que asumen las decisiones públicas en el territorio y la incidencia diferencial que, según su composición de clase, pueden llegar a tener los grupos de beneficiarios/as en la implementación de políticas habitacionales. Observando el desarrollo del Procrear en La Plata, la tesis abre discusiones en torno al rol de la política urbana, la atención diferencial que se realiza desde el sector público frente a demandas que logran posicionarse en la agenda política con mayor o menor celeridad gracias a los recursos movilizados por las diferentes clases sociales, y los impactos territoriales de las políticas modeladas por estrategias de diferenciación socioespacial.

Desde las “Coordenadas teóricas y metodológicas de la investigación” presentadas en el capítulo 1, la autora anuncia un estudio pragmático-pragmatista sobre dos colectivos de beneficiarios del Procrear (Lxs Terxs y COLP $)^{2}$ para analizar la relación entre clases medias, políticas públicas y producción de ciudad. Presenta al 
Estado como campo de interacción al que asiste una multiplicidad de actores que inciden en su permanente formación, y las interacciones que pueden hacer de una cuestión, un problema público. Expone coordenadas para entender "la vida social del mundo político", en tanto relaciones personales atravesadas por la clase social que facilitan el acceso a bienes y servicios, y la división social del espacio como resultado de la relación entre espacio urbano y espacio social en el capitalismo.

El Capítulo 2 "El Procrear en la ciudad de La Plata. Suelo urbano, subsidio a la demanda y escenario local" contextualiza el análisis. Presenta al Procrear, sus líneas de financiamiento y cómo estas se fueron diversificando conforme se iban leyendo las dificultades para su implementación en los municipios (debidas a la escasez de suelo urbano asequible); y expone los rasgos de la política bruerista y el modo en que se gestionó la política urbana. ${ }^{3}$ Así, se pueden conocer las restricciones generales de los sectores medios platenses para acceder a la vivienda y, en particular, las que se encontraron a la hora de conseguir suelo para construir con financiamiento del Procrear. También se muestra cómo Lxs Terxs supieron aprovechar la decadencia política de la gestión municipal como ventana de oportunidad para posicionar sus demandas e imponerle sus propias coordenadas en pos de un régimen urbanístico particular. Todo en menos de 60 días.

En el Capítulo 3 "De la demanda al problema público. La emergencia de 'Lxs Terxs' y la coproducción de normativa urbana" se recorre la conformación del colectivo Lxs Terxs y su veloz incidencia en la sanción de la ordenanza. Siguiendo a Melé (2016), se argumenta que el conflicto en torno al acceso al suelo urbano fue "productivo social, jurídica y territorialmente": produjo un actor político con formas de implicación y negociaciones propias que logró modelar la normativa urbana y, con ello, la producción de ciudad. Se reconstruye el proceso de movilización de capital social y cultural (Bourdieu, 2000) para conseguir la reacción de los actores políticos locales: las redes de relaciones personales que permitieron llegar rápidamente al entorno del intendente y, concomitantemente, poner el tema en los medios de comunicación locales. La movilización de capital social se apoyó en una suerte de solidaridad de clase con los agentes estatales y en los saberes expertos del grupo, conformado por profesionales y trabajadores/as estatales que comparten códigos y hablan la misma lengua de la estatalidad. Por su parte, el capital cultural puesto en marcha para dar forma a la ordenanza se vislumbra a partir de las tareas asumidas por miembros del grupo, quienes lograron juridificar y burocratizar el conflicto mediante sus propias prácticas, sin necesidad de recurrir a profesionales externos al colectivo y sin tener pérdidas de traducción técnica (Latour, 1998). ${ }^{4}$

Es interesante la discusión que plantea respecto de los vínculos clientelares que, cuando comprometen sectores populares, se erigen sobre mediadores o traductores de la burocracia estatal (Auyero, 2016), mientras que en el caso analizado, donde la composición del grupo es claramente de clase media profesional, es la afinidad de clase la que permite que burocracias estatales y beneficiarios/as actúen como una comunidad de profesionales, sin necesidad de traducción, lo cual desdibuja el vínculo clientelar o, al menos, lo modifica drásticamente respecto de lo analizado para otras clases sociales.

Los siguientes dos capítulos son los que van a mostrar más crudamente las consecuencias espaciales del accionar de los colectivos de beneficiarios/as del Procrear en tanto productores de una periferia desarticulada del tejido urbano y una ciudad difusa. El capítulo 4 "Juntarse para alejarse y reproducir la clase. Estrategias residenciales en los márgenes asignados por el mercado" muestra cómo Lxs Terxs resolvieron la tensión entre la oportunidad de ser propietarios/as de viviendas (dada por el Procrear) y el lugar periférico asignado por el mercado de suelo. Rechazaron las ofertas de terrenos a través del municipio ${ }^{5}$ y generaron un proceso activo de diferenciación social, simbólica y espacial que saldó el desajuste entre sus trayectorias residenciales previas, sus expectativas de inscripción territorial y el lugar que el mercado les estaba asignando. Presenta las valorizaciones de las localizaciones aceptables para los/as miembros del colectivo y así evidencia la capacidad de lectura de la dinámica urbana que tuvieron al comprar tierra emplazada en áreas de fuerte valorización en curso; muestra la resignación de la centralidad a cambio de que las futuras mudanzas se realicen "entre iguales” y cuánto primó la pertenencia de clase en el proceso de suburbanización residencial de estas familias, que prefirieron cargar el peso de vivir en la periferia (tiempos de viaje, transporte público deficiente, servicios 
inexistentes y/o a su cargo) antes que convivir con sectores populares en barrios más cercanos al centro y dotados de servicios.

El capítulo 5 "La Vía 3. Un proceso de regularización mediado y legitimado por el Procrear" analiza el proceso ultraveloz que dio cabida a la rezonificación de suelo adquirido previamente en condominio. Muestra cómo los condominios preexistentes funcionaron como inspiradores de Lxs Terxs sobre la posibilidad de adquirir suelo periférico para construir barrios de clase media y, viceversa, la pelea por la ordenanza de estos últimos como habilitadora de una posibilidad hasta entonces impensada de dotar de indicadores urbanísticos de uso residencial a la tierra rural de propiedad indivisa. Catorce condominios que luego de la ordenanza pasaron a engrosar la lista de once fracciones rurales que, dispersas por la periferia platense y conviviendo con usos agrícolas e industriales, hoy determinan hacia dónde va a crecer la ciudad "formal". 6

Se presenta a la vía 3 como la manera de regularizar formas novedosas de irregularidad urbana que, a diferencia de la irregularidad de las urbanizaciones populares, no está deslegitimada, precisamente, por tratarse de prácticas de clases medias con suficientes recursos discursivos para justificarlas en tanto resultado de la expulsión de estos sectores de sus trayectorias residenciales previas y de sus expectativas de ser propietarios de viviendas en la ciudad. Planteado de esta manera, es ineludible el contrapunto con las magras respuestas del mismo gobierno municipal a la irregularidad del hábitat popular (Relli Ugartamendía, 2019) que simultáneamente aumentaba en cantidad y densidad, además de empeorar las condiciones de sus emplazamientos (Del Río y González, 2018).

La tesis propone temas para seguir indagando. Preguntarse por el habitar estos barrios periféricos, cómo sobrellevan sus pobladores/as la pérdida de centralidad, el rumbo de las organizaciones vecinales, los vínculos con los entornos rurales, etc. Despierta curiosidad geográfica el proceso de valorización del suelo intersticial resultante entre los emplazamientos de los nuevos loteos y el tejido urbano consolidado, quién capitalizará esa valorización y cómo la gestionará el municipio, si es que está dispuesto a hacerlo.

Algo que llama a la reflexión es la imposibilidad de estos colectivos de mirar a la ciudad en su conjunto, aun con los saberes expertos para hacerlo. Esos saberes (técnicos, políticos, militantes) no se pusieron al servicio de una mirada integral de la ciudad y se optó por aprovechar la oportunidad de ser propietarios/as de casas en terrenos grandes. Se mencionan las "contradicciones personales internas" comentadas por algunos/ as entrevistados/as, sobre todo, militantes sociales y políticos/as embarcados en esta empresa, pero que al final fueron resueltas subordinando sus adscripciones ideológicas ante la consolidación de un proceso de suburbanización que hipoteca el futuro de la ciudad.

En el devenir del Procrear, como rasgo novedoso, se fueron proponiendo y ensayando modalidades de intervención con mayor presencia pública para la gestión urbana (desarrollos urbanísticos, oferta de lotes con servicios), pero en La Plata los colectivos de beneficiarios/as las rechazaron, justamente, por la incidencia estatal que suponen, que choca con la reclamada libertad de elección de los sectores medios que se posicionan como portadores de un "status de ciudadanía" distinto respecto de los sectores tradicionalmente atendidos por las políticas habitacionales. La tesis muestra esta contradicción entre quienes necesitan al Estado para cumplir sus objetivos, pero lo rechazan al querer intervenir en sus decisiones de localización residencial, ya que para eso estuvo el mercado y la lectura que ellos/as supieron hacer de su dinámica. Asimismo, habla del hacer político de actores gubernamentales que no estaban dispuestos a pagar el costo que pudo haber significado no aceptar las condiciones de Lxs Terxs y COLP, cumplir un rol de conducción de la implementación del Procrear y, con ello, de orientación del crecimiento de la ciudad, en definitiva, por activar sus competencias en el campo de la planificación urbana.

\section{REFERENCIAS}

Auyero, J. (2016). Pacientes del Estado. Buenos Aires: Eudeba. 
Bourdieu, P. (2000). Las formas del capital. Capital económico, capital cultural y capital social. En Bourdieu, P. (Coord.), Poder, derecho y clases sociales. Bilbao: Desclée de Brouwer.

Del Río, J. P. y Langard, F. (2016). Del poder de los ladrillos a la ciudad banco. Las implicancias del boom inmobiliario en el acceso a la vivienda de los sectores asalariados. En Féliz, M., López, E. y García, M. (Coords.), Desarmando el modelo: desarrollo, conflicto y cambio social tras una década de neodesarrollismo. Buenos Aires: El Colectivo.

Del Río, J. P. y González, P. (2018). Los asentamientos informales en el Gran La Plata. Una geografía cambiante con más de tres décadas de persistencia. En Cravino, M.C. (Org.), La ciudad (re)negada. Aproximaciones al estudio de asentamientos populares en nueve ciudades argentinas. Los Polvorines: UNGS.

Latour, B. (1998). De la mediación técnica: filosofía, sociología y genealogía. En Domenech, M.y Tirado, F.J. (Comps.), Sociología asimétrica. Barcelona: Gedisa.

Melé, P. (2016). ¿Qué producen los conflictos urbanos? En Carrión, F. y Erazo, J. (Coords.), El derecho a la ciudad en América Latina. Visiones desde la politica. México: UNAM, PUEC, CIALC, IDRC/CRDI.

Relli Ugartamendía, M. (2019). Desencuentros entre política urbana y política de regularización del hábitat popular en La Plata, Argentina. Anales de Geografía de la Universidad Complutense, 39(2), 439-462. https://doi.org/1 0.5209 /aguc.66946

\section{Notas}

1 Al frente del municipio durante dos periodos consecutivos, entre 2007 y 2015.

2 A través de un extenso trabajo de campo que le permitió contar con diversas fuentes: entrevistas en profundidad; observaciones de campo en asambleas, reuniones, actos y sesiones del Consejo Deliberante; análisis de documentos internos de los colectivos estudiados y de las interacciones entre sus miembros en los grupos de la red social Facebook.

3 Caracterizada por la flexibilización de la normativa y desregulación del mercado de suelo, con sus consecuentes repercusiones en los precios y ampliación de la brecha urbana (Del Río y Langard, 2016).

4 Así lograron incluir la "Vía 2" en la ordenanza 11.094/13, que es la que otorga uso residencial a las fracciones rurales adquiridas por Lxs Terxs para la construcción de viviendas financiada por el Procrear.

5 Lo que se conoció como "Vía 1" en la implementación local del programa, en la que el municipio organizaba la lista de oferentes de terrenos ya urbanizados.

6 Se rezonificaron unos 1.787 lotes a través de la ordenanza 11.094/13, localizados mayoritariamente en los ejes noroeste y sur de la periferia platense.

\section{BY-NC-SA}

